\title{
Insights into the basal activity and activation mechanism of the $\beta 1$ adrenergic receptor using native mass spectrometry
}

\author{
Agni F. M. Gavriilidou ${ }^{1 \dagger}$, Hanna Hunziker ${ }^{1 \dagger}$, Daniel Mayer ${ }^{2,3 \dagger}$, Ziva Vuckovic ${ }^{2,3}$, Dmitry B. \\ Veprintsev ${ }^{2,3 \&^{*}}$, Renato Zenobi ${ }^{*}$

\begin{abstract}
${ }^{1}$ ETH Zurich, Department of Chemistry and Applied Biosciences, Zurich, Switzerland
${ }^{2}$ Laboratory of Biomolecular Research, Paul Scherrer Institut, Villigen, Switzerland

${ }^{3}$ ETH Zurich, Department of Biology, Zurich, Switzerland NG7 2UH, UK.
\end{abstract} \\ \& current address: Centre of Membrane Proteins and Receptors (COMPARE), University of Birmingham and \\ University of Nottingham, Midlands, UK and School of Life Sciences, University of Nottingham, Nottingham,
}

\begin{abstract}
In the absence of orthosteric ligands, most $G$ protein-coupled receptors (GPCRs) exist in an equilibrium of different conformational states. This equilibrium is shifted by an agonist towards the active state or by an inverse agonist towards the inactive state. The basal activity of the receptor, and its ability to activate intracellular signaling pathways, is defined by the probability that a fraction of the receptor adopts the active state in the absence of ligand. Despite breakthroughs in native MS of membrane proteins, GPCRtransducing complexes have not been studied by this approach until very recently. Here, we investigated different conformational states of the turkey $\beta 1$ adrenergic receptor (t $\beta 1 \mathrm{AR}$ ) in complex with two transducing partners, a $\mathrm{G}$ protein mimicking nanobody, Nb80, and an engineered truncated Gs protein (miniGs), in the presence of the full agonist isoprenaline by native MS. Interestingly, complex formation with both transducing partners was also observed in the absence of agonist, and allowed us to quantify basal activity of t $\beta 1 \mathrm{AR}$. We followed the step-wise disassembly of the transducing complexes by increasing the concentration of the inverse agonist S32212 in the presence of a constant concentration of isoprenaline. This allowed us to determine the relative binding affinity of S32212 in comparison to isoprenaline by native MS. Our approach provides a fast and sensitive way to detect complexes, study their stability in the presence of different ligands, and determine relative ligand affinities. Native mass spectrometry thus has the potential to become a useful tool to screen for orthosteric and allosteric GPCR drugs.
\end{abstract}

Corresponding Authors

*Renato Zenobi (zenobi@org.chem.ethz.ch)

Dmitry B. Veprintsev (dmitry.veprintsev@nottingham.ac.uk),

${ }^{\dagger}$ Agni F. M. Gavriilidou, Hanna Hunziker, Daniel Mayer contributed equally to this work and all three should be considered first authors

This document is the accepted manuscript version of the following article:

Gavriilidou, A. F. M., Hunziker, H., Mayer, D., Vuckovic, Z., Veprintsev, D. B., \& zenobi, R. (2019). Insights into the basal activity and activation mechanism of the $\beta 1$ adrenergic receptor using native mass spectrometry. Journal of the American Society for Mass spectrometry, 30(3), 529-537.

https://doi .org/10.1007/s13361-018-2110-z 


\section{Introduction}

GPCRs represent the most abundant class of integral membrane proteins in the human genome. They account for roughly $40 \%$ of all prescription drugs, aimed at treating various diseases such as cardiac dysfunction, obesity, asthma, and others [1, 2]. GPCRs are highly dynamic allosterically-controlled proteins that regulate a number of different transduction pathways, primarily mediated by heterotrimeric $\mathrm{G}$ proteins and arrestins, upon binding to extracellular ligands [3, 4]. In the absence of ligands many GPCRs show basal activity resulting in activation of $\mathrm{G}$ proteins, rationalized as a fraction of receptor molecules adopting an active conformation purely by chance [5]. Based on their pharmacologic responses, ligands can be divided into different subgroups: full agonists, partial agonists, antagonists and inverse agonists. Full and partial agonists bind to the orthosteric binding pocket and stabilize an active-like conformation of the receptor that results in the recruitment and activation of several types of G proteins. Antagonists occupy the same orthosteric binding pocket without affecting the equilibrium between the active and inactive states of the receptor protein and its basal activity. Inverse agonists stabilize the inactive state of the receptor and reduce or even completely silence basal activity [6-10]. Biased agonists change the overall balance of effector protein binding dictating which specific G proteins and arrestins are recruited and activated, relative to the reference agonist (typically, the fullest agonist available). In contrast, allosteric modulators are ligands that bind elsewhere on the receptor and primarily affect signaling induced by orthosteric ligands. Both biased ligands and allosteric modulators offer very promising avenues for novel GPCR drug development due to their potential for increased selectivity and as a consequence their ability to show fewer undesirable sideeffects. Therefore, it is important to be able to detect preferentially formed receptortransducing complexes because they ultimately define pharmacological effects of the ligand. 
Mass spectrometry (MS) is a rapid, sensitive, and high resolution analytical method and therefore a powerful tool to directly measure the binding stoichiometry and relative affinity of biomolecular complexes $[11,12]$.

Although substantial progress has been made, native mass spectrometry of membrane proteins is still challenging, in part due to their amphiphilic nature. Moreover, detergents that are used to solubilize membrane proteins have a suppressing effect on the ionization and result in the formation of adduct peaks, which renders peak annotation difficult. Over the years, several protocols were developed that allow the ionization of membrane proteins while preserving their structural integrity [13]. It has been shown that by maintaining detergent micelles in solutions above the critical micelle concentration, interactions between cytoplasmic and transmembrane subunits can be preserved and that such complexes can be released intact into the gas phase by subjecting them to multiple gas collisions to strip away the detergent [14]. Optimizing the conditions for preserving interactions during transmission into the gas phase has allowed for the determination of subunit stoichiometry, lipid and drug binding of intact membrane protein complexes $[15,16]$. Amphipols, bicelles and nanodiscs have also been utilized to transport intact membrane protein complexes to the gas phase [17, 18]. At the same time, the resolution of mass spectrometers has dramatically improved, allowing one to distinguish the binding of low molecular weight ligands to large proteins [19]. Conditions for preserving noncovalent interactions of small molecules to a receptor has been previously described [20]. For example, it became possible to study the effect of endogenous lipids on the G protein selectivity and coupling by native MS. Receptors were found to preferably bind to engineered $G$ subunits depending on the nature and the concentration of the endogenous lipids [21]. These effects of lipids on receptors will help understand function, G-protein selectivity and drug targeting of receptors. These advances 
motivated us to investigate the possibility of studying GPCR signaling complexes by the native MS approach.

For this study, we chose a well-behaved engineered version of the turkey $\beta_{1}$ adrenergic receptor $[22,23]\left(\mathrm{t} \beta_{1} \mathrm{AR}\right)$ that is capable of activating its heterotrimeric $\mathrm{G}$ protein [24]. Initial experiments were performed with the nanobody-80 (Nb80), which has been previously reported to stabilize the active $G$ protein complex-like conformation of human $\beta_{2}$ and turkey $\beta_{1}$ adrenergic receptor $[24,25]$. Additionally, we used an engineered minimal version of $\mathrm{G}_{\mathrm{s}}$ composed solely of the RAS domain of the Ga subunit [26]. This $\operatorname{miniG}_{\mathrm{s}}$ protein was shown to induce similar pharmacological and structural changes in GPCRs as the entire heterotrimeric G protein complex and is a useful tool to study GPCR-transducing complexes without relying on the much less stable trimeric G protein complex [27]. We used these two artificial transducing partners to measure the ability of the $\beta_{1} A R$ to form its transducing complex in the presence and absence of an agonist, reflecting both its agonist activation state and its basal activation state. Further, we monitored the equilibrium shift from an active to an inactive state of the receptor by competing for isoprenaline binding to the $t \beta_{1} A R$ with an inverse agonist. This allowed us to determine the relative binding affinity of the inverse agonist S32212 versus the agonist isoprenaline by native MS.

\section{Experimental}

Expression and purification of t $\beta_{1}$ AR (Vector: pcDNA4; cell line: stable HEK293 GNTI-). Cells were grown on $15 \mathrm{~cm}$ plates (90\% confluency) and detached with trypsin, resuspended in DMEM medium with 10\% FBS and centrifuged for 5 minutes at $800 \mathrm{xg}$. The pellet was resuspended in $100 \mathrm{~mL}$ of medium for suspension cultures (PEM without L-glutamine (Gibco) with 10\% FBS, antibiotics (penicillin-streptomycin-fungizone) and glutaMAX ${ }^{\mathrm{TM}}$ 
(Gibco)). Later, FBS was reduced to $5 \%$. Cells were grown in $2 \mathrm{~L}$ shaker flasks $(1 \mathrm{~L}$ of cell culture volume) in an incubator at $37^{\circ} \mathrm{C}$ with $5 \% \mathrm{CO}_{2}$. Following resuspension, cells were counted and diluted to $0.8-0.9 \times 10^{6}$ cells $/ \mathrm{mL}$. Cells doubled approximately every 24 hours and were never diluted below $0.6-0.7 \times 10^{6}$ cells $/ \mathrm{mL}$. Cells were induced with tetracycline and sodium butyrate when they reached $3-3.5 \times 10^{6}$ cells $/ \mathrm{mL}$ and were left to express for 50 hours. Cells were harvested for 30 minutes at $3000 \mathrm{~g}$ and $4^{\circ} \mathrm{C}$ using a Sorvall RC $3 \mathrm{C}$ Plus centrifuge and $\mathrm{H}-6000 \mathrm{~A}$ rotor. The pellet was transferred to a $50 \mathrm{~mL}$ falcon tube and washed three times with ice cold PBS. For each wash step cells were resuspended with a $25 \mathrm{~mL}$ pipette and then centrifuged for $15 \mathrm{~min}$ at $3220 \mathrm{~g}$ and $4^{\circ} \mathrm{C}$ in an Eppendorf $5810 \mathrm{R}$ centrifuge. Washed pellets were frozen at $-80^{\circ} \mathrm{C}$.

Pellets were lyzed and membranes were prepared. Cell membranes were solubilized in solubilization buffer (20 mM HEPES pH 7.5, $300 \mathrm{mM} \mathrm{NaCl}, 1 \mathrm{mM}$ EDTA, 10\% glycerol $(\mathrm{v} / \mathrm{v})$, protease inhibitors and $2 \%$ decyl-maltoside $(\mathrm{DM})(\mathrm{w} / \mathrm{v}))$. For each $\mathrm{g}$ of membranes 8 $\mathrm{mL}$ of the solubilization buffer was used. Membranes were resuspended well with a Torrex and then incubated for 1 hour at $4^{\circ} \mathrm{C}$ on a roller mixer. Solubilized material was ultracentrifuged for 1 hour at $185000 \mathrm{~g}$ using a Beckman Coulter Optima XE-100 or Optima XL-100K ultracentrifuge and Ti45 rotor. GFP fluorescence of the supernatant was measured and the amount of the protein in the sample was calculated. One $\mathrm{mL}$ of 1D4 resin was added to one mg of protein and left to incubate at $4{ }^{\circ} \mathrm{C}$ for 3 hours on a roller mixer. The resin was loaded into BioRad column and the supernatant was eluted.

The resin with bound protein was washed with 10 column volumes (CV) of washing buffer (20 mM HEPES pH 7.5, $300 \mathrm{mM} \mathrm{NaCl}, 0.2 \%$ (w/v) DM). $1.5 \mathrm{CV}$ of cleavage buffer $(20 \mathrm{mM}$ HEPES pH 7.5, $300 \mathrm{mM} \mathrm{NaCl}, \mathrm{HRV}-3 \mathrm{C}$ protease (1:10 ratio), $2.8 \mathrm{mM}$ of reduced glutathione and $0.45 \mathrm{mM}$ of oxidized glutathione) was added to the resin and left to incubate 
on the roller at $4^{\circ} \mathrm{C}$ overnight. The sample was concentrated using $50 \mathrm{kDa}$ Vivaspin concentrators to approximately $15 \mathrm{mg} / \mathrm{mL}$ and a total volume of approximately $400 \mu \mathrm{l}$, centrifuged at $21000 \mathrm{~g}$ using an Eppendorf 5415R centrifuge for $10 \mathrm{~min}$ and further purified by gel filtration using a self-packed Superdex 200, Tricorn 10/300 column. This was run with buffer (20 mM HEPES pH 7.5, $300 \mathrm{mM} \mathrm{NaCl}$, and $0.2 \%(\mathrm{w} / \mathrm{v}) \mathrm{DM}$ ) with a flow of 0.4 $\mathrm{mL} / \mathrm{min}$ and a fraction size of $0.4 \mathrm{~mL}$. Fractions showing appropriate UV signal were pooled and concentrated in a $0.5 \mathrm{~mL}$ concentrator, $50 \mathrm{kDa}$ cut off (Vivaspin 500, Sartorius) to a concentration suitable for further processing $(200-300 \mu \mathrm{M})$.

Expression and purification of Nb80: The Nb80 was expressed with a C-terminal His-tag in the periplasm of E. coli strain WK6. The cells were cultured in "terrific broth" media supplemented with $0.1 \%$ (w/v) glucose, $2 \mathrm{mM} \mathrm{MgCl}_{2}$ and $100 \mu \mathrm{M}$ ampicillin. The temperature of the culture was reduced to $28^{\circ} \mathrm{C}$ after reaching an $\mathrm{OD}_{600}$ of 0.70 and $1 \mathrm{mM}$ IPTG was added for induction. The cells were harvested on the next day and lysed in $50 \mathrm{mM}$ Tris* $\mathrm{HCl} \mathrm{pH} 8.0,12.5 \mathrm{mM}$ EDTA and $0.125 \mathrm{M}$ sucrose. After centrifugation the $\mathrm{Nb} 80$ was purified by a nickel affinity chromatography and a size-exclusion chromatography on a Superdex75 60/300 column (20 mM HEPES pH 7.45, $100 \mathrm{mM} \mathrm{NaCl})$. The protein was concentrated to $100 \mathrm{mg} / \mathrm{ml}$ with a $20 \mathrm{ml}, 10 \mathrm{kDa}$ cut-off concentrator and flash-frozen in liquid nitrogen.

Expression and purification of miniG $_{\mathbf{s}}$ (Vector: pET-15b (Ampicillin resistance); cell line: Nico (DE3)._A freshly transformed plate was used to inoculate a $500 \mathrm{ml}$ starting culture grown in $2 \mathrm{~L}$ Erlenmeyer flask at $30^{\circ} \mathrm{C}$ and shaking speed $160 \mathrm{rpm}$ overnight. $40 \mathrm{ml}$ of starting culture were used to inoculate $500 \mathrm{ml}$ of $\mathrm{TB}$ media containing carbenicillin $(50 \mu \mathrm{g} / \mathrm{ml})$ in a $2 \mathrm{~L}$ baffled flask $(12 \mathrm{x})$. The culture was run at $37^{\circ} \mathrm{C} / 160 \mathrm{rpm}$ for $3-4$ hours till it reached an $\mathrm{OD}_{600}$ of above 2.0. Then the temperature was reduced to $20^{\circ} \mathrm{C}$ and 
induction was done with $50 \mu \mathrm{M}$ IPTG. The cells were harvested on the next day after approx. 20-24 hours post-induction by centrifugation (3000 g for $20 \mathrm{~min}$ ). Pellets were frozen and stored at $-20^{\circ} \mathrm{C}$.

The cell pellets of $6 \mathrm{~L}$ culture were thawed in a beaker filled with cold water. Afterwards, the cell pellets were transferred to a $250 \mathrm{~mL}$ beaker. Two tablets of EDTA free protease inhibitor (Complete-Roche) and $8 \mathrm{mM}$ beta-mercaptoethanol were added before the cells were lyzed with sonication ( $3 \times 5 \mathrm{~min}, 1 \mathrm{~s}$ pulse / $0.5 \mathrm{~s}$ pause). An ultracentrifuge spin was performed to remove the insoluble fraction (Ti45 tubes $/ 1$ hour at $4^{\circ} \mathrm{C}$ and $40 \mathrm{k}$ ). The supernatant was filtered with 3 (or 4) $0.45 \mu \mathrm{m}$ syringe filters and $30 \mathrm{mM}$ imidazole was added before it was loaded onto a $5 \mathrm{ml} \mathrm{Ni-NTA} \mathrm{FF} \mathrm{crude} \mathrm{column.} \mathrm{The} \mathrm{column} \mathrm{was} \mathrm{washed} \mathrm{with} 10 \mathrm{CV}$ of buffer A (20 mM HEPES pH 7.0, $500 \mathrm{mM} \mathrm{NaCl,} 40 \mathrm{mM}$ Imidazole, $1 \mu \mathrm{M}$ GDP, $10 \%$ glycerol, 8 $\mathrm{mM}$ beta-mercaptoethanol). A step elution with IMAC B buffer (same as A but with $500 \mathrm{mM}$ imidazole) was performed. The pooled elution of all fractions was dialyzed (size exclusion buffer: $20 \mathrm{mM}$ HEPES pH 7.0, $150 \mathrm{mM} \mathrm{NaCl}, 50 \mu \mathrm{M}$ GDP, 10\% glycerol, $8 \mathrm{mM}$ betamercaptoethanol) overnight in the presence of the TEV protease. Next morning, the protein was concentrated to approx. $30-40 \mathrm{mg} / \mathrm{ml}$ and injected onto a 16/60 Suderdex 75 column. $1 \mathrm{ml}$ fractions were collected and the monomeric peak fractions were concentrated with a spin concentrator (Vivaspin, $10 \mathrm{kDa}$ cut-off). The concentrated protein was flash frozen in liquid nitrogen and stored at $-80^{\circ} \mathrm{C}$.

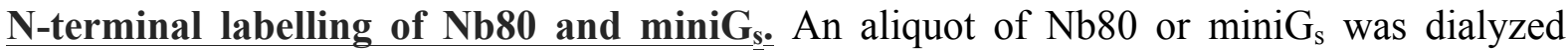
against $50 \mathrm{mM} \mathrm{NaH} \mathrm{PO}_{4} / \mathrm{Na}_{2} \mathrm{HPO}_{4} \mathrm{pH} 9.0,150 \mathrm{mM} \mathrm{NaCl}, 8 \mathrm{mM}$ 2-mercaptoethanol over night. Next day, after determining the protein concentration, 0.8 molar equivalent of 5carboxyfluorescein-succinimidyl ester (ThermoFischer) dissolved in DMSO was added. The reaction was stopped by adding $100 \mathrm{mM}$ Tris* $\mathrm{HCl} \mathrm{pH} 7.0$ after $20 \mathrm{~min}$ of reaction at room 
temperature. The protein was separated from the free dye by performing size-exclusion chromatography (10/30 Superdex200). The protein fractions were collected and flash frozen in liquid nitrogen.

Mass Spectrometry. Mass spectra were recorded on a hybrid quadrupole time-of-flight mass spectrometer (Q-TOF ULTIMA, Waters/Micromass, Manchester, U.K.) in positive ion mode. $2 \mu$ of sample solution were directly infused with gold/palladium-coated borosilicate glass nano ESI emitters (Thermo Fisher Scientific, Reinach, Switzerland) using a commercial nano ESI ion source (Waters/Micromass, Manchester, UK). The source temperature was kept at $25{ }^{\circ} \mathrm{C}$. The MS parameters were adjusted as follows: capillary voltage, $2.5 \mathrm{kV}$; cone voltage, $90 \mathrm{~V}$; RF1 lens energy, $50 \mathrm{~V}$; collision voltage, $300 \mathrm{~V}$; the pressure in the collision cell was set to $3.5 \times 10^{-2}$ mbar. Each spectrum was recorded for 2 minutes. The raw data were exported from MassLynx 4.0 and further processed with Matlab R2016b.

\section{Results \& Discussion}

In order to reproducibly detect ions of the $\mathrm{t} \beta_{1} \mathrm{AR}$ and its complexes with $\mathrm{Nb} 80$ and $\mathrm{mini}_{\mathrm{s}}$, it was essential to optimize buffer conditions (buffer agent, $\mathrm{pH}$, detergent and its concentration) and instrument settings. The receptor, $\mathrm{N} 80$ and $\mathrm{miniG}_{\mathrm{s}}$ were dialyzed overnight against the MS optimized buffer. Different detergents require correspondingly different amounts of activation energy to successfully release the receptor from its micelle to obtain clearly defined ion peaks. We explored two maltoside detergents, decyl-maltoside (DM) and dodecyl-maltoside (DDM). The critical micelle concentration (CMC) for DM is ten times higher than that obtained for DDM. It has been shown that detergents with higher CMC values produce better-quality mass spectra [13]. While in both detergents $t \beta_{1} A R$ peaks could be clearly observed, the peaks of DM encapsulated receptor had lower charges than the DDM encapsulated one. This implies a more compact conformation of the $t \beta_{1} \mathrm{AR}$ in DM micelles 
compared to DDM micelles (Figure 1). The origin of this change in charge state is currently unclear; it may be the result of an altered solvent-accessible area or altered interactions between micelle and protein.

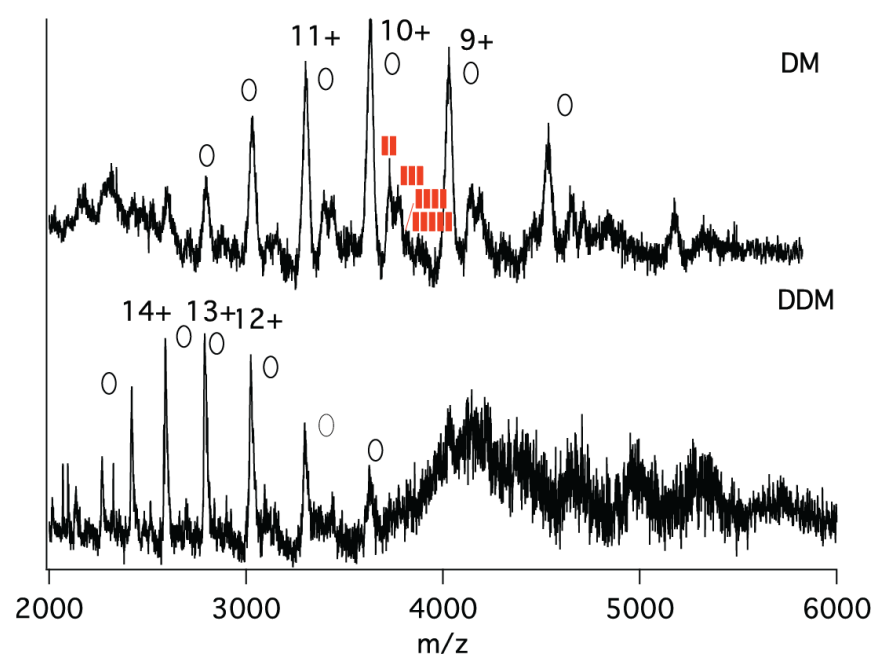

Figure 1: Spectra of $25 \mu \mathrm{M}$ t $\beta_{1} \mathrm{AR}$ in $0.2 \%(\mathrm{w} / \mathrm{v}) \mathrm{DM}$ (upper spectrum) and $0.02 \%(\mathrm{w} / \mathrm{v}$ ) DDM (lower spectrum). Ion peaks with fewer charges were generated for the receptor in DM detergent compared to DDM suggesting a more compact conformation. Clusters of detergent molecules were observed in both of the spectra and in all the subsequent spectra. Receptor ion peaks are represented with white circles and each DM molecule is represented with a red rectangle.

In general, it was important to keep the detergent concentration slightly above its CMC level but not too high, in order to not suppress the ionization process (Figure 2a). We choose DM at a concentration between $0.1 \%$ to $0.12 \%(\mathrm{w} / \mathrm{v})$ for subsequent experiments. The applied collision energy for all executed experiments was optimized and a value of $300 \mathrm{~V}$ was chosen, which efficiently liberated the receptor and its transducing complexes from their detergent micelles (Figure 2b). 

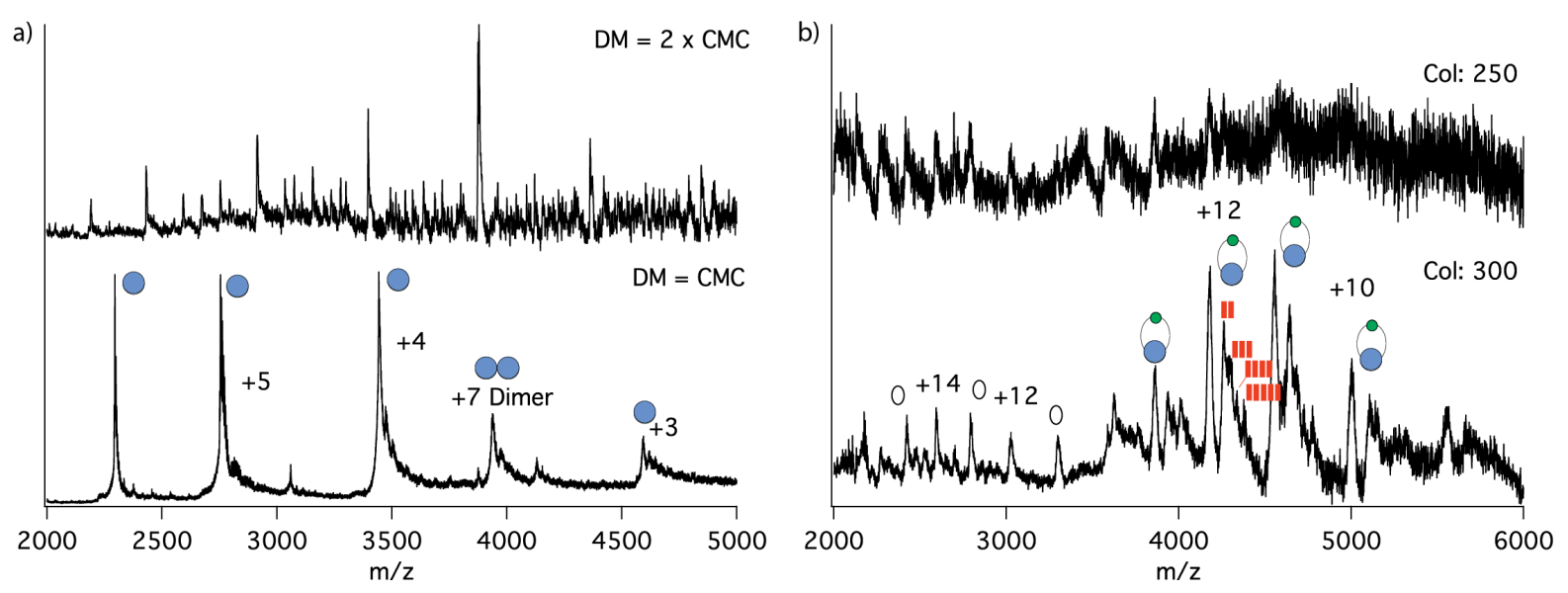

Figure 2: Effect of detergent concentrations and collision energy $(\mathrm{Col})$ on the mass spectra. a) At $2 \times \mathrm{CMC}$ of $\mathrm{DM}(0.2 \%(\mathrm{w} / \mathrm{v}))$ the $\mathrm{Nb} 80$ was trapped in detergent micelles (upper spectrum) and the spectrum is dominated by DM cluster peaks. At DM concentration equal to its $\mathrm{CMC} \mathrm{Nb80} \mathrm{ion} \mathrm{peaks} \mathrm{(blue} \mathrm{circles)} \mathrm{were} \mathrm{clearly} \mathrm{observed} \mathrm{(lower} \mathrm{spectrum).} \mathrm{b)} \mathrm{The}$ collision energy $(300 \mathrm{~V})$ was optimized in order to maximize the transmission of the protein and complex ions (lower spectrum). At a collision energy of $250 \mathrm{~V}$ (upper spectrum) the complex was trapped in detergent micelles and the peaks were not resolved. The receptor ions peaks are represented with white circles, $\mathrm{Nb80}$ ion peaks with blue circles and the agonist isoprenaline with green circles. Clusters with DM molecules are indicated with red boxes.

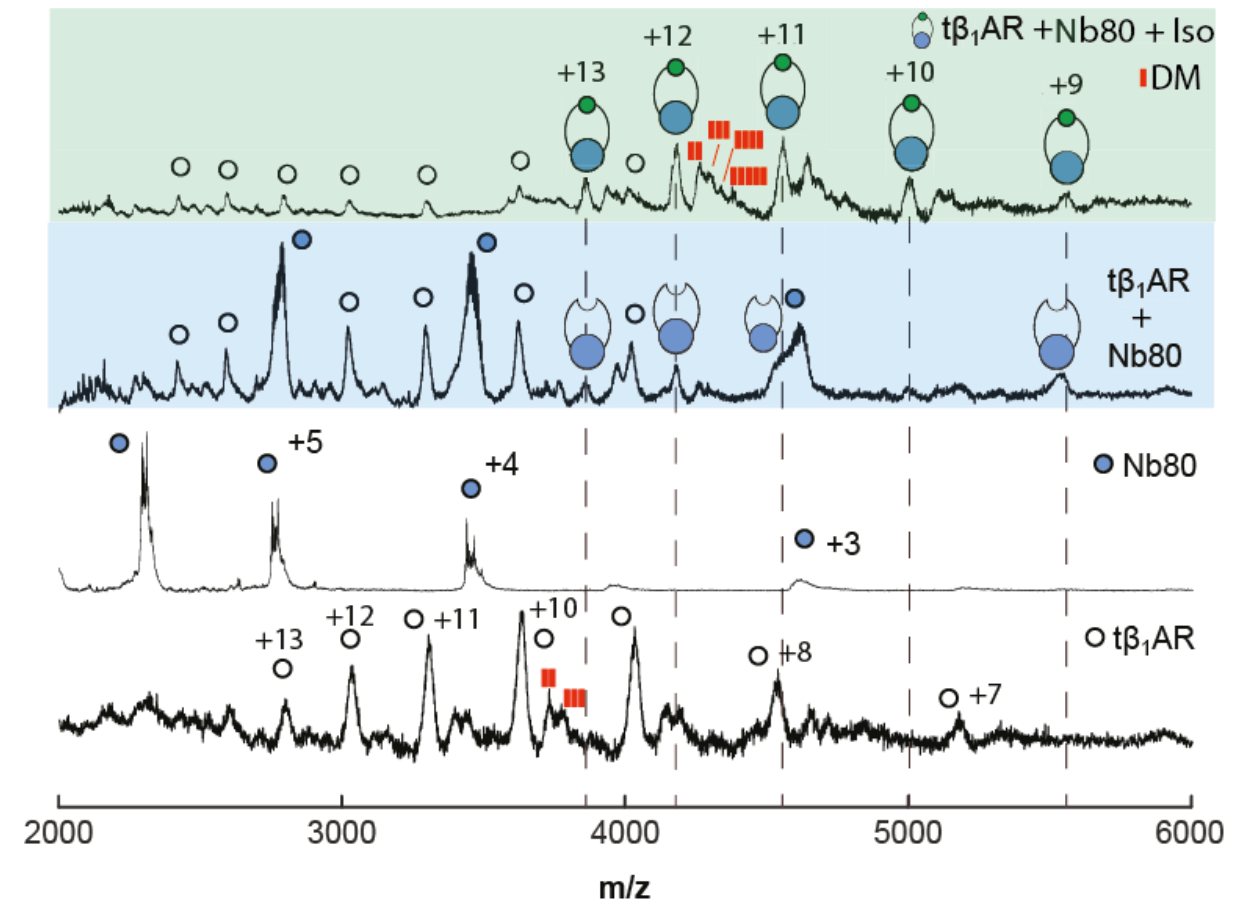

Figure 3: Spectra of $\beta_{1} \mathrm{AR}$ (white circles) and $\mathrm{Nb} 80$ (blue circles) in the presence (green highlighted spectrum) and absence (blue highlighted spectrum) of the agonist isoprenaline $(25 \mu \mathrm{M})$. Control spectra of the individual proteins $\mathrm{Nb} 80(12.5 \mu \mathrm{M})$ and $\mathrm{t}_{1} \mathrm{AR}(25 \mu \mathrm{M})$ are shown in the lower half. Clusters of DM molecules (red rectangles) were observed in each spectrum except for $\mathrm{Nb80}$ alone. 
a)
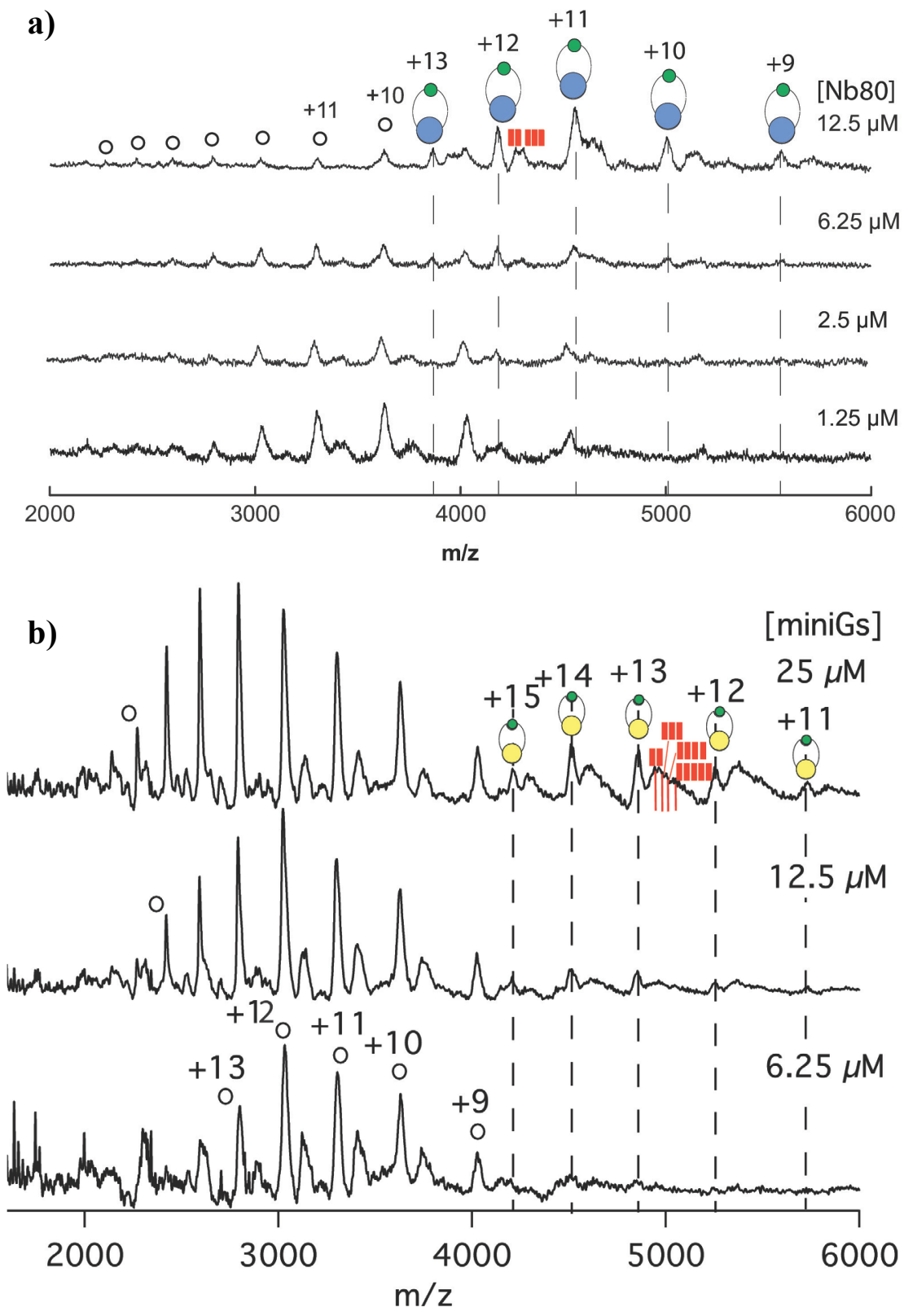

Figure 4: a) Titration of $\mathrm{Nb80}$ against $\mathrm{t} \beta_{1} \mathrm{AR}$ (25 $\mu \mathrm{M}$, empty circles) in buffer $200 \mathrm{mM}$ $\mathrm{NH}_{4} \mathrm{Ac}$ supplemented with DM in the presence of isoprenaline $(25 \mu \mathrm{M})$. At higher concentration of $\mathrm{Nb} 80$ the complex peaks are increased. b) Titration of miniG $_{\mathrm{s}}$ against $\mathrm{t} \beta_{1} \mathrm{AR}$ (25 $\mu \mathrm{M}$, empty circles) in buffer, $200 \mathrm{mM}$ $\mathrm{NH}_{4} \mathrm{Ac}$ supplemen-ted with DM in the presence of isoprenaline (25 $\mu \mathrm{M})$. At higher concentration of miniG $_{\mathrm{s}}$ the complex peaks are increased.

In the presence of isoprenaline $(25 \mu \mathrm{M})$, we observed complex formation for both transducing partners, $\mathrm{Nb} 80$ and $\mathrm{miniG}_{\mathrm{s}}$, using optimized buffer conditions $\left(200 \mathrm{mM} \mathrm{NH}_{4} \mathrm{Ac}\right.$ $\mathrm{pH} 7.5$, supplemented with $0.1 \%$ to $0.12 \%(\mathrm{w} / \mathrm{v}) \mathrm{DM})$. We were able to detect almost complete complex formation for $\mathrm{Nb80}$, as judged by the absence of the peak of the free receptor (Figure 3). Less complex could be observed in the case of the engineered $\operatorname{miniG}_{\mathrm{s}}$ protein compared to $\mathrm{Nb80}$, at similar protein concentrations (Figure $\mathbf{4 a} \boldsymbol{\&} \mathbf{4 b}$ ). 
This was a surprising result because we determined almost identical affinities for both transducing partners in solution with the $t \beta_{1} A R$ in presence of saturating concentrations of the agonist isoprenaline using a fluorescence anisotropy based affinity assay (Figure 5). There are several possible reasons for the lower intensity in the mass spectral peaks that we observed for the miniG $\mathrm{s}_{\mathrm{s}} \mathrm{t} \beta_{1} \mathrm{AR}$ complex in comparison to the $\mathrm{Nb80}-\mathrm{t} \beta_{1} \mathrm{AR}$ complex. Although both the $\mathrm{Nb80}$ and $\mathrm{miniG}_{\mathrm{s}}$ bind to the same location of the receptor, they most likely form different interactions to stabilize the active conformation of these receptors due to their different receptor residue contacts. This may result in different stabilities of the complexes in vacuum compared to their stabilities in solution. Alternatively, this observation may be affected by the different energy required to release the complexes from the micelle or due to a lower ionization efficiency of the $\operatorname{miniG}_{\mathrm{s}}$ complex versus the $\mathrm{Nb} 80$ complex. It is also possible that the molar activity of $\mathrm{miniG}_{\mathrm{s}}$ in solution is lower than that of $\mathrm{Nb} 80$.
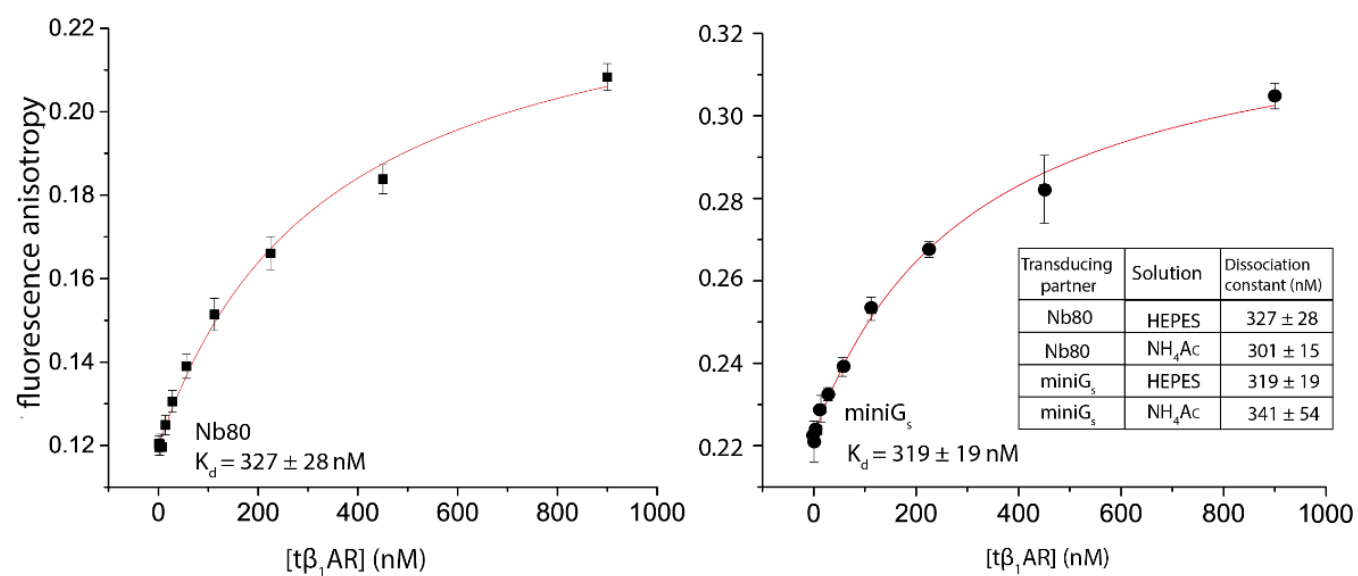

Figure 5: Formation of the Nb80-FITC $\beta_{1} A R$ complex in $20 \mathrm{mM}$ HEPES, pH 7.4, $150 \mathrm{mM}$ $\mathrm{NaCl}, 0.2 \%(\mathrm{w} / \mathrm{v}) \mathrm{DM}$, plus $400 \mu \mathrm{M} \mathrm{VitC}$ in the presence of $40 \mu \mathrm{M}$ isoprenaline. The affinity of the fluorescently labeled $\mathrm{Nb} 80(1 \mu \mathrm{M})$ was determined to be approximately $300 \mathrm{nM}$ under two different buffer conditions. The miniG $_{\mathrm{s}}$ protein showed affinities in a similar range using the same assay formats. All measurements were performed in triplicate. 
In addition to observing complex formation in the presence of agonist, we were able to monitor the basal activity of the $\beta_{1} \mathrm{AR}$ by observing its transducing complexes $(\mathrm{Nb} 80$ and $\mathrm{mini}_{\mathrm{s}}$ ) in the absence of agonist. This means that $\mathrm{t} \beta_{1} \mathrm{AR}$ is in principle capable of recruiting its signaling partners even though no agonist is present (Figures $\mathbf{3}$ \& 6a). From triplicate measurements, we estimated that approximately $7 \pm 2.8 \%$ of the total receptor formed a complex, reflecting its basal activity. Previously, basal activity only has been indirectly detected by a cooperative effect of increased ligand binding affinity or increased constitutive activity [28].

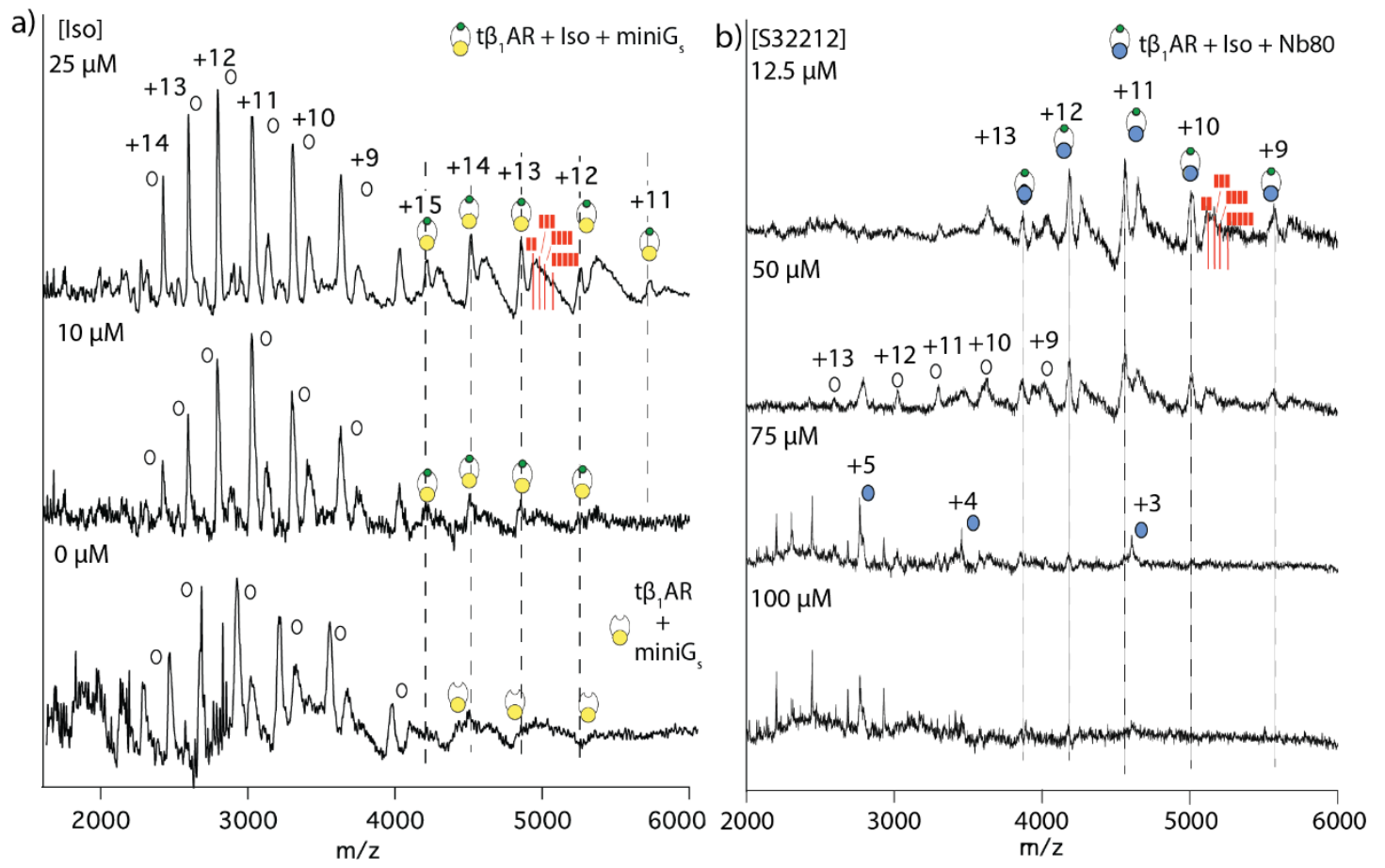


Figure 6: a) Observed transducing complex of ${ }_{1} \beta_{1} A R(25 \mu \mathrm{m})$ with $\operatorname{miniG}_{\mathrm{s}}(25 \mu \mathrm{M})$ in the presence of different concentrations of the agonist isoprenaline $(0 ; 10$; and $25 \mu \mathrm{M})$. Although the transducing complex is formed more prominently in the presence of added ligand (top spectrum) compared to its absence (bottom spectrum), there are clearly complex signals visible even without agonist. b) Disruption of the $t \beta_{1} A R-N b 80$ complex upon addition of the inverse agonist S32212. The inverse agonist S32212 directly competes with the agonist ( $25 \mu \mathrm{M}$ isoprenaline) resulting in the gradual stabilization of the inactive state of the receptor. At higher concentrations of S32212 the complex peaks disappeared and the free receptor $\mathrm{t} \beta_{1} \mathrm{AR}$ peaks and free $\mathrm{Nb80}$ peaks appear. Complex formation was achieved with $25 \mu \mathrm{M}$ t $\beta_{1} A R$ and $12.5 \mu \mathrm{M}$ Nb80. Ion peaks of $t \beta_{1} A R$ are shown with white circles, miniG $_{s}$ with yellow circles, $\mathrm{Nb80}$ with blue circles, isoprenaline with green circles and clusters of DM molecules as red rectangles.

Further, we could follow the increase in complex formation with increasing the agonist concentration (Figure 6a). The maximum was reached at equimolar concentrations of isoprenaline to receptor $\left([\right.$ isoprenaline $\left.]=\left[\mathrm{t} \beta_{1} \mathrm{AR}\right]=25 \mu \mathrm{M}\right)$. We also observed the stepwise dissociation of the transducing complex by increasing concentrations of the inverse agonist S32212. A competition experiment of S32212 with the complex is shown in Figure 6b. At equimolar concentrations of isoprenaline and S32212 ([isoprenaline $]=[\mathrm{S} 32212]=25 \mu \mathrm{M})$ we observed only a partially disruption of the signaling complex (approx. 40\%). That allowed us to conclude that the affinity of the inverse agonist S32212 for the receptor is close to that of isoprenaline for the signaling complex. This value is reported to be around $0.5 \mu \mathrm{M}$ for this particular construct of $\mathrm{t}_{1} \mathrm{AR}$ [24]. A full dissociation of the complex was observed at a S32212 concentration of $75 \mu \mathrm{M}$, which corresponded to a three-fold higher concentration of the competing ligand. The receptor in the presence of inverse agonist is preferentially stabilized in its inactive state and does not form any complex with either of the transducing partners $\left(\mathrm{Nb} 80 / \mathrm{miniG}_{\mathrm{s}}\right)$ (Figure 7, black frame). The fact that the agonist binding affects the stability of the transducing complex provides an exciting possibility to detect signaling bias of the ligands by observing their relative stabilization of the complexes with different miniG proteins. 


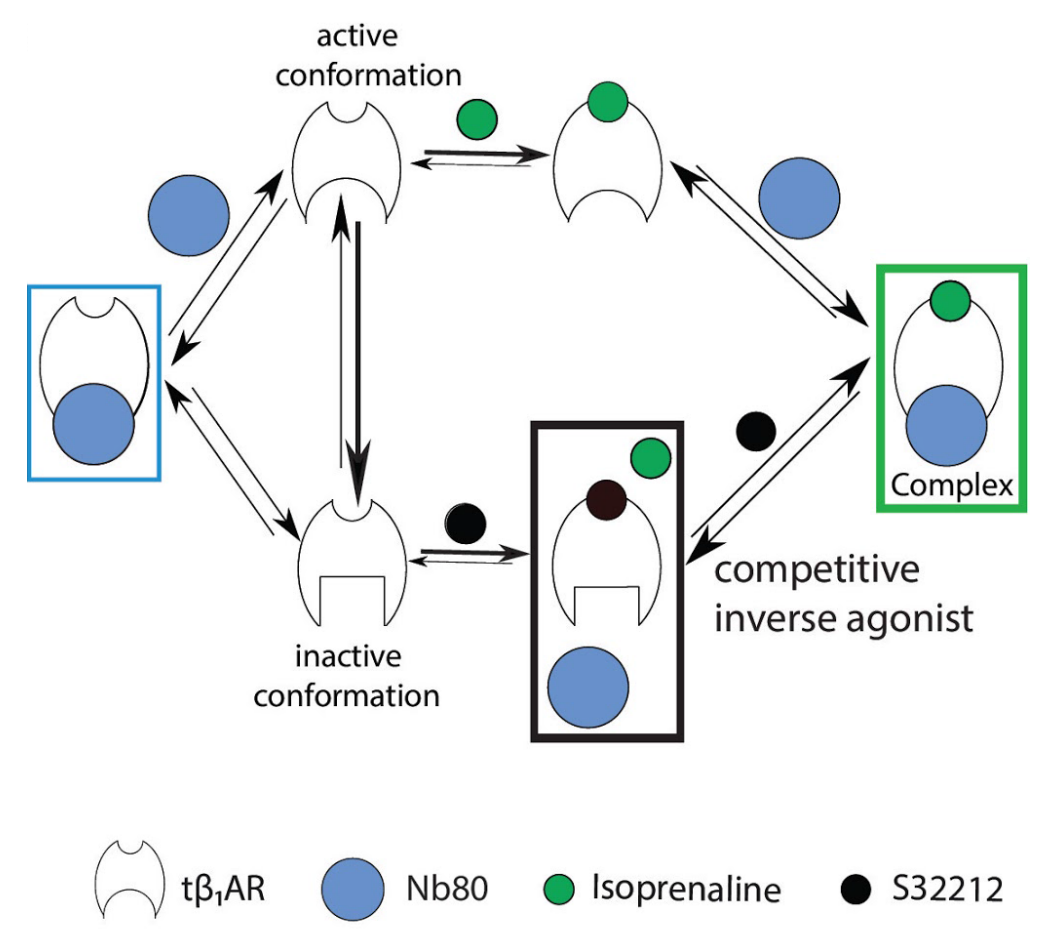

Figure 7: Schematic representation of the binding mechanism. The apo state receptor is shown in an equilibrium of active and inactive conformations, whereas the inactive is in general much more occupied (indicated by arrow thickness). Agonist binding results in a preferential stabilization of a more active-like population of the receptor to which $\mathrm{Nb} 80$ can bind to a greater extent (green frame). Nb80 can also bind in the absence of any agonist, which can be explained by the inherent basal activity of the receptor (blue frame). The inverse agonist S32212 stabilizes a more inactive conformation of the receptor and results in the inhibition of $\mathrm{t} \beta_{1} \mathrm{AR}-\mathrm{Nb} 80$ complex formation (black frame).

\section{Conclusions}

In this study, we reported the successful characterization of GPCR-transducing complexes by native MS. We observed complexes of the $\mathrm{t} \beta_{1} \mathrm{AR}$ with its transducing partners in absence of any ligand which provided insights into its basal activity. Additionally, we were able to follow not only the complex formation by adding an agonist, but as well the disruption of the complex by increasing concentration of inverse agonist. This allowed us to compare the individual affinities of the ligands for the $t \beta_{1} A R$. This approach could be extended to detect allosteric modulators, which should also affect complex formation. Native MS has a great 
potential to provide an orthogonal approach for the comparison of ligand affinities and their potential signaling outputs. It is a rapid technique and does not require production of radioactive or fluorescently labelled ligands which require a significant development effort. Potentially, this work paves a way to a native MS based ligand screen for GPCRs, as well as the development of fine grained screens for biased ligands. This technique would be applicable for the discovery of orthosteric drugs, as well as of allosteric modulators, which remain very promising avenues for GPCR drug discovery.

\section{Acknowledgments}

We thank David Sykes for critical reading of the manuscript, Chris Tate for sharing the sequences for the miniG proteins, and Jan Stayer and Brian Kobilka for sharing the plasmid for the Nb80. We thank the Swiss National Science Foundation (grants no. 200020_159929

and 200020_178765 to RZ and 31003A_159748 and CRSII3_141898 to DBV) for financial support of this research. 


\section{REFERENCES}

1. Hopkins, A.L., Groom, C.R.: The druggable genome. Nat. Rev. Drug Discov. 1, 727-730 (2002). doi: $10.1038 / \mathrm{nrd} 892$

2. Hauser, A.S., Attwood, M.M., Rask-Andersen, M., Schiöth, H.B., Gloriam, D.E.: Trends in GPCR drug discovery: New agents, targets and indications. Nat. Rev. Drug Discov. 16, 829842 (2017). doi:10.1038/nrd.2017.178

3. Gilman, A.G.: G proteins: transducers of receptor-generated signals. Annu. Rev. Biochem. 56, 615-649 (1987). doi:10.1146/annurev.bi.56.070187.003151

4. $\quad$ Arun K., S., Kunhong, X., Lefkowitz, R.J.: Emerging paradigms of $\beta$-arrestin-dependent seven transmembrane receptor signaling. Trends Biochem Sci. 36, 457-469 (2011). doi:10.1016/j.biotechadv.2011.08.021

5. Milligan, G.: Constitutive activity and inverse agonists of $\mathrm{G}$ protein-coupled receptors: a current perspective. Mol. Pharmacol. 64, 1271-6 (2003). doi:10.1124/mol.64.6.1271

6. Neubig, R.R., Spedding, M., Kenakin, T., Christopoulos, A.: International Union of Pharmacology Committee on Receptor Nomenclature and Drug Classification. XXXVIII. Update on Terms and Symbols in Quantitative Pharmacology. Pharmacol. Rev. 55, 597-606 (2003). doi:10.1124/pr.55.4.4

7. Khan, S.M., Sleno, R., Gora, S., Zylbergold, P., Laverdure, J.-P., Labbe, J.-C., Miller, G.J., Hebert, T.E.: The Expanding Roles of G Subunits in G Protein-Coupled Receptor Signaling and Drug Action. Pharmacol. Rev. 65, 545-577 (2013). doi:10.1124/pr.111.005603

8. Dupré, D.J., Robitaille, M., Rebois, R.V., Hébert, T.E.: The Role of G $\beta \gamma$ Subunits in the Organization, Assembly, and Function of GPCR Signaling Complexes. Annu. Rev. Pharmacol. Toxicol. 49, 31-56 (2009). doi:10.1146/annurev-pharmtox-061008-103038

9. Kenakin, T.: A Pharmacology Primer 4th Edition Techniques for More Effective and Strategic Drug Discovery. (2014)

10. Kenakin, T.: Pharmacology in Drug Discovery 1st Edition Understanding Drug Response. (2011)

11. Loo, J.A.: Studying noncovalent protein complexes by electrospray ionization mass spectrometry. Mass Spectrom. Rev. 16, 1-23 (1997)

12. Hernández, H., Robinson, C. V: Determining the stoichiometry and interactions of macromolecular assemblies from mass spectrometry. Nat. Protoc. 2, 715-26 (2007). doi:10.1038/nprot.2007.73

13. Laganowsky, A., Reading, E., Hopper, J.T.S., Robinson, C. V: Mass spectrometry of intact membrane protein complexes. Nat. Protoc. 8, 639-651 (2013)

14. Barrera, N.P., Di Bartolo, N., Booth, P.J., Robinson, C. V: Micelles protect membrane complexes from solution to vacuum. Science. 321, 243-6 (2008). doi:10.1126/science.1159292

15. Barrera, N.P., Isaacson, S.C., Zhou, M., Bavro, V.N., Welch, A., Schaedler, T.A., Seeger, M.A., Miguel, R.N., Korkhov, V.M., van Veen, H.W., Venter, H., Walmsley, A.R., Tate, C.G., Robinson, C. V: Mass spectrometry of membrane transporters reveals subunit stoichiometry and interactions. Nat. Methods. 6, 585-587 (2009). doi:10.1038/nmeth.1347

16. Marcoux, J., Wang, S.C., Politis, A., Reading, E., Ma, J., Biggin, P.C., Zhou, M., Tao, H., Zhang, Q., Chang, G., Morgner, N., Robinson, C. V: Mass spectrometry reveals synergistic effects of nucleotides, lipids, and drugs binding to a multidrug resistance efflux pump. Proc. 
Natl. Acad. Sci. 110, 9704-9709 (2013). doi:10.1073/pnas.1303888110

17. Leney, A.C., McMorran, L.M., Radford, S.E., Ashcroft, A.E.: Amphipathic polymers enable the study of functional membrane proteins in the gas phase. Anal. Chem. 84, 9841-9847 (2012). doi:10.1021/ac302223s

18. Hopper, J.T.S., Sokratous, K., Oldham, N.J.: Charge state and adduct reduction in electrospray ionization-mass spectrometry using solvent vapor exposure. Anal. Biochem. 421, 788-790 (2012). doi:10.1016/j.ab.2011.10.034

19. Rose, R.J., Damoc, E., Denisov, E., Makarov, A., Heck, A.J.R.: High-sensitivity Orbitrap mass analysis of intact macromolecular assemblies. Nat. Methods. 9, 1084-1086 (2012). doi:10.1038/nmeth.2208

20. Yen, H., Hopper, J.T.S., Liko, I., Allison, T.M., Zhu, Y., Wang, D., Stegmann, M., Mohammed, S., Wu, B., Robinson, C. V: Ligand binding to a G protein - coupled receptor captured in a mass spectrometer. Sci. Adv. 1-6 (2017)

21. Yen, H.-Y., Hoi, K.K., Liko, I., Hedger, G., Horrell, M.R., Song, W., Wu, D., Heine, P., Warne, T., Lee, Y., Carpenter, B., Plückthun, A., Tate, C.G., Sansom, M.S.P., Robinson, C. V: PtdIns(4,5)P 2 stabilizes active states of GPCRs and enhances selectivity of G-protein coupling. Nature. 559, 423-427 (2018). doi:10.1038/s41586-018-0325-6

22. Warne, T., Serrano-Vega, M.J., Baker, J.G., Moukhametzianov, R., Edwards, P.C., Henderson, R., Leslie, A.G.W., Tate, C.G., Schertler, G.F.X.: Structure of a $\beta 1$-adrenergic G-proteincoupled receptor. Nature. 454, 486-491 (2008). doi:10.1038/nature07101

23. Miller, J.L., Tate, C.G.: Engineering an ultra-thermostable $\beta 1$-adrenoceptor. 413, (2011). doi:10.1016/j.jmb.2011.08.057

24. Isogai, S., Deupi, X., Opitz, C., Heydenreich, F.M., Tsai, C.-J., Brueckner, F., Schertler, G.F.X., Veprintsev, D.B., Grzesiek, S.: Backbone NMR reveals allosteric signal transduction networks in the $\beta 1$-adrenergic receptor. Nature. 314, 1-17 (2016). doi:10.1038/nature16577

25. Rasmussen, S.G.F., Choi, Fung, Pardon, Casarosa, Chae, Devree, Rosenbaum, Thian, Kobilka, Schnapp, A., Konetzki, Sunahara, R.K., Gellman, Pautsch, Steyaert, J., Weis, Kobilka: Structure of a nanobody-stabilized active state of the $\beta(2)$ adrenoceptor. Nature. $469,175-180$ (2011). doi:10.1038/nature09648

26. Carpenter, B., Tate, C.G.: Engineering a minimal G protein to facilitate crystallisation of G protein-coupled receptors in their active conformation. Protein Eng. Des. Sel. 29, 583-594 (2016). doi:10.1093/protein/gzw049

27. Carpenter, B., Nehmé, R., Warne, T., Leslie, A.G.W., Tate, C.G.: Structure of the adenosine A 2A receptor bound to an engineered $G$ protein. 536, 104-107 (2016). doi:10.1038/nature18966

28. Devree, B.T., Mahoney, J.P., Vélez-ruiz, G.A., Rasmussen, S.G.F., Kuszak, A.J., Edwald, E., Fung, J., Manglik, A., Masureel, M., Du, Y., Matt, R.A., Pardon, E., Steyaert, J., Kobilka, B.K., Roger, S.K.: Allosteric coupling from $\mathrm{G}$ protein to the agonist binding pocket in GPCRs. Nature. 535, 182-186 (2016). doi:10.1038/nature18324 